\title{
RESTORATION OF THE NOSE BY TRANSPLANTATION OF SKIN FROM THE FOREHEAD IN THE YEAR 1881.
}

\author{
Br T. PRIDGIN TEALE, IEEDS.
}

W. H., in 1876 , when at the age of 18 , was kicked in the cheek whilst tending a horse. This led to the destruction of the fleshy and bony part of the nose, leaving a large hole in the centre of the face. He became a patient of the Huddersfield Infirmary, where various measures were tried under the care of the late Mr. Kilner Clarke.

On Jan. 28, 1878, he came into the Leeds General Infirmary for three months and then became an out-patient until 1881. In May of that year the new nose was made by Mr. Pridgin 'Teale, and nine days afterwards the stitches were removed. W'ithin three weeks the raw gap on the forehead was healed over.

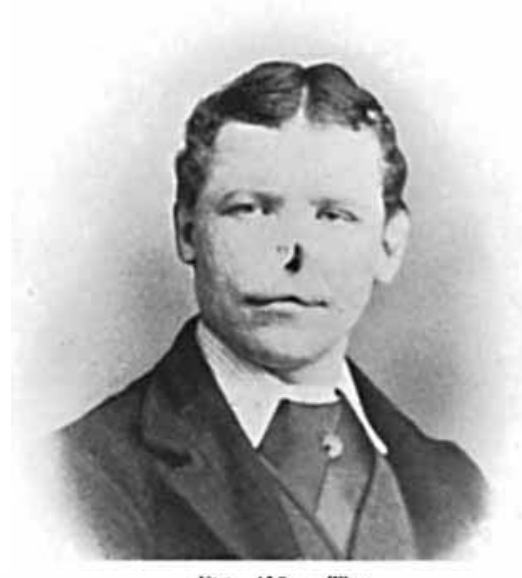

Fit. 453. - The patient ( 1 ..11.) at the late of the operation in 1881 .

In a recent letter to Mr. Teale (1921) Mr. H. expresses his feelings as follows :-

"Since the operation I have been able to take my place amongst the world of men, earn my living, and to follow the occupation of a platelayer on the railway, having been rescued from being merely an outcast and a pariah, pointed at, derided, and scorned by the thoughtless and the ignorant."

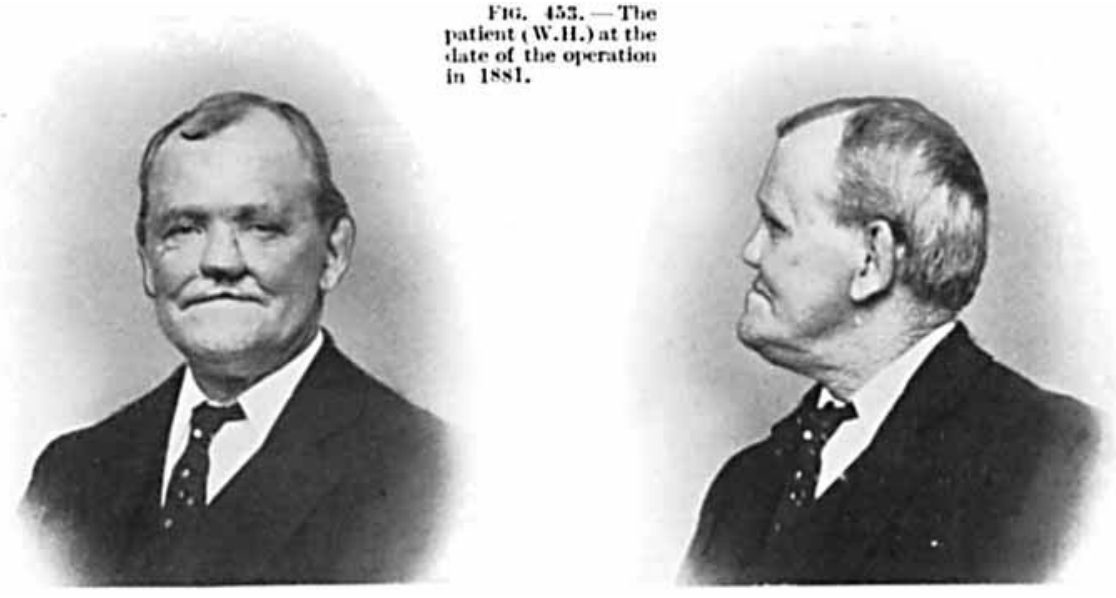

HIGS. $454,45, \ldots-1$. I. forty years later in 1921 .

There is one lesson which I would enforce by this case. About the time of this operation it was taught by some surgeons that as soon as the flap was safely grown into place the pedicle should be severed. I taught that to do this was to risk subsequent shrinking of the new nose. This teaching was enforced in my address at Nottingham on "Atrophy induced by Cicatrix, and its Surgical Value". This view was sound, but it must be modified in view of the experience of Thiersch's grafts, and transplantation of thin shavings of skin.

voL. IX. - No. 35 . 